\title{
Orgaaninen seleeni mahdollistaa seleenirikastettujen munien tuotannon
}

Eija Valkonen ${ }^{1)}$, Merja Eurola ${ }^{2)}$ ja Jarmo Valaja ${ }^{1)}$

${ }^{1)}$ MTT, Kotieläintuotannon tutkimus, 31600 Jokioinen, etunimi.sukunimi@mtt.fi

${ }^{2)}$ MTT, Palveluyksikkö, 31600 Jokioinen, etunimi.sukunimi@mtt.fi

\section{Tiivistelmä}

Seleeni on välttämätön hivenaine niin eläimille kuin ihmisillekin. Kasveissa seleeni esiintyy orgaanisessa muodossa, enimmäkseen selenometioniinina. Kasvit ottavat sekä orgaanista että epäorgaanista seleeniä maaperästä. Rehun kasviraaka-aineiden seleeni ei yleensä riitä täyttämään munivien kanojen tarvetta. Tähän asti seleeniä on lisätty rehuun epäorgaanisessa muodossa. Marraskuussa 2006 EU:ssa hyväksyttiin rehun lisäaineeksi orgaaninen seleeninlähde seleenirikastettu hiiva. Ravinnon orgaaninen seleeni on eläimille ja ihmisille käyttökelpoisempaa kuin epäorgaaninen seleeni.

Rehun osuus on yli puolet munantuotannon muuttuvista kustannuksista. Tilalla viljellyn viljan käyttäminen kanojen rehuksi voi tuoda säästöä rehukustannuksiin verrattuna täysrehuruokintaan. Viljaa täydentämään on totuttu käyttämään rehutiivisteitä. Vilja-tiivisteseoksen valmistus ostetaan usein rahtimylläriltä ja seoksessa kotoinen vilja on jauhettuna. Yksiköiden kasvaessa tällainen tiivisteviljaruokinta ei välttämättä ole enää käytännöllistä. Viljan syöttäminen kokonaisina jyvinä teollisen puolitiivisteen lisäksi toisi säästöjä jauhatuskustannuksen jäädessä pois. Kokonaisen viljan käytön etuna voi myös olla tehostunut lihasmahan toiminta.

Tässä kokeessa tutkittiin rehuun lisätyn epäorgaanisen ja orgaanisen seleenin vaikutuksia kanojen munantuotantoon ja niiden siirtymistä kananmunaan. Lisäksi verrattiin täysrehuruokintaa ja puolitiivisteen käyttöä kokonaisen vehnän tai ohran kanssa.

Koe-eläiminä oli 1200 LSL-kanaa, jotka kokeen alkaessa olivat 21 viikon ikäisiä. Kanat pidettiin varustelluissa häkeissä. Häkkimalleja oli käytössä kaksi, toinen kahdeksalle ja toinen 14 kanalle. Koe kesti koko tuotantokauden (52 viikkoa). Koekäsittelyt muodostuivat seleeninlähteen (orgaaninen tai epäorgaaninen), ruokinnan (täysrehu tai puolitiiviste-vilja) ja viljalajin (ohra tai vehnä) sekä häkkimallin yhdistelmistä.

Täysrehuruokinnalla rehunkulutus oli pienempää kuin puolitiiviste-viljaruokinnalla. Myös rehunmuuntosuhde oli täysrehuruokinnalla parempi kuin puolitiiviste-viljaruokinnalla. Muihin tuotannon tunnuslukuihin ruokinta ei vaikuttanut. Kokonaista ohraa puolitiivisteen kanssa saaneissa ryhmissä rehunkulutus oli suurempi kuin ryhmissä, jotka saivat puolitiivisteen kanssa kokonaista vehnää. Ohran matalampi energiapitoisuus vehnään verrattuna selittänee tämän eron. Muissa tuotantotuloksissa ohra ja vehnä eivät eronneet toisistaan.

Seleenilähde ei vaikuttanut kanojen munintaprosenttiin. Orgaanista seleeniä saaneiden kanojen rehunkulutus oli keskimäärin suurempi kuin epäorgaanista seleeniä saaneiden kanojen. Orgaanista seleeniä saaneet kanat munivat ensimmäisen rehuvaiheen aikana suurempia munia kuin epäorgaanista seleeniä saaneet kanat. Seleeninlähteen vaikutus munan keskipainoon ei kuitenkaan ollut tilastollisesti merkitsevä koko kokeen tuloksia tarkastellessa.

Seleeninlähde vaikutti selvästi kananmunan seleenipitoisuuteen; orgaanista seleeniä saaneiden kanojen munissa seleeniä oli selvästi enemmän kuin epäorgaanista seleeniä saaneiden. Orgaaninen seleeninlähde mahdollistaa seleenirikastettujen kananmunien tuotannon.

Asiasanat: munantuotanto, seleeni, kokonainen vilja, ohra, vehnä 


\section{Johdanto}

Seleeni on välttämätön hivenaine niin eläimille kuin ihmisillekin. Kasveissa seleeni esiintyy orgaanisessa muodossa, aminohappoihin sitoutuneena, pääasiassa selenometioniinina (Buckley 2000). Kasvit ottavat sekä orgaanista että epäorgaanista seleeniä maaperästä (Jacques 2002). Rehun kasviraakaaineiden seleeni ei yleensä riitä täyttämään munivien kanojen tarvetta. Tähän asti seleeniä on lisätty rehuun epäorgaanisessa muodossa; natriumseleniittinä tai natriumselenaattina. Marraskuussa 2006 EU:ssa hyväksyttiin rehun lisäaineeksi orgaanisen seleenin lähde seleenirikastettu hiiva (Saccharomyces cerevisiae, Sel-Plex $\left.{ }^{\circledR}\right)$. Ravinnon orgaaninen seleeni on eläimille ja ihmisille käyttökelpoisempaa kuin epäorgaaninen seleeni (Surai 2002). Selenometioniini, joka ei välittömästi metaboloidu, varastoituu valkuaissynteesin kautta kudosten valkuaisaineisiin metioniinin tapaan (Schrauzer 2000).

Rehun osuus on yli puolet munantuotannon muuttuvista kustannuksista. Tilalla viljellyn viljan käyttäminen kanojen rehuksi voi tuoda säästöä rehukustannuksiin verrattuna täysrehuruokintaan. Viljaa täydentämään on totuttu käyttämään rehutiivisteitä. Vilja-tiivisteseoksen valmistus ostetaan usein rahtimylläriltä ja seoksessa kotoinen vilja on jauhettuna. Yksiköiden kasvaessa tällainen tiivisteviljaruokinta ei välttämättä ole enää käytännöllistä. Viljan syöttäminen kokonaisina jyvinä teollisen puolitiivisteen lisäksi toisi säästöjä jauhatuskustannuksen jäädessä pois. Kokonaisen viljan käytön etuna voi myös olla tehostunut lihasmahan toiminta. Suurin osa lihasmahasta lähtevistä partikkeleista on kooltaan alle $40 \mu \mathrm{m}$ huolimatta rehun alkuperäisestä fysikaalisesta rakenteesta (Hetland ym. 2002). Lihasmahan toiminnan tehostuminen näkyy $\mathrm{mm}$. lisääntyneenä ruokasulan takaisinvirtauksena ja siitä johtuvana suurempana sappihappojen määränä lihasmahassa (Hetland ym. 2003). Lihasmahan toiminnan vaikutus ravintoaineiden sulavuuteen perustunee juuri lisääntyneeseen takaisinvirtaukseen. Takaisinvirtauksen ansiosta ruuansulatusnesteiden vaikutusaika pitenee ja sen seurauksena ravintoaineiden sulaminen on tehokkaampaa.

Tässä kokeessa tutkittiin rehuun lisätyn epäorgaanisen ja orgaanisen seleenin vaikutuksia kanojen munantuotantoon ja niiden siirtymistä kananmunaan. Lisäksi verrattiin täysrehuruokintaa ja puolitiivisteen käyttöä kokonaisen vehnän tai ohran kanssa.

\section{Aineisto ja menetelmät}

Koe-eläiminä oli 1200 LSL-kanaa, jotka kokeen alkaessa olivat 21 viikon ikäisiä. Kanat pidettiin varustelluissa häkeissä Maa- ja elintarviketalouden tutkimuskeskuksen Kotieläintuotannon tutkimuksen koekanalassa. Käytössä oli kaksi erilaista häkkimallia, toinen kahdeksalle ja toinen 14 kanalle. Koe kesti koko tuotantokauden (52 viikkoa). Koe jaettiin 13:een neljän viikon mittaiseen koejaksoon. Munantuotanto ja rehunkulutus määritettiin kunkin jakson keskiarvoina. Koekäsittelyt muodostuivat seleeninlähteen (orgaaninen tai epäorgaaninen), ruokinnan (täysrehu tai puolitiiviste-vilja) ja viljalajin (ohra tai vehnä) sekä häkkimallin yhdistelmistä (taulukko 1).

Taulukko 1. Koekäsittelyt

\begin{tabular}{|c|c|c|c|c|c|}
\hline Käsittely & Ruokintakäsittely & Ruokinta & Vilja & Seleenin lähde & Häkkityyppi \\
\hline 1 & 1 & Täysrehu & - & Orgaaninen (Sel-plex) & Triotec (8 kanaa) \\
\hline 2 & 1 & Täysrehu & - & Orgaaninen (Sel-plex) & Munakunta (14 kanaa) \\
\hline 3 & 2 & Täysrehu & - & Epäorgaaninen & Triotec (8 kanaa) \\
\hline 4 & 2 & Täysrehu & - & Epäorgaaninen & Munakunta (14 kanaa) \\
\hline 5 & 3 & Puolitiiviste + vilja & Ohra & Orgaaninen (Sel-plex) & Triotec (8 kanaa) \\
\hline 6 & 3 & Puolitiiviste + vilja & Ohra & Orgaaninen (Sel-plex) & Munakunta (14 kanaa) \\
\hline 7 & 4 & Puolitiiviste + vilja & Vehnä & Orgaaninen (Sel-plex) & Triotec (8 kanaa) \\
\hline 8 & 4 & Puolitiiviste + vilja & Vehnä & Orgaaninen (Sel-plex) & Munakunta (14 kanaa) \\
\hline 9 & 5 & Puolitiiviste + vilja & Ohra & Epäorgaaninen & Triotec (8 kanaa) \\
\hline 10 & 5 & Puolitiiviste + vilja & Ohra & Epäorgaaninen & Munakunta (14 kanaa) \\
\hline 11 & 6 & Puolitiiviste + vilja & Vehnä & Epäorgaaninen & Triotec (8 kanaa) \\
\hline 12 & 6 & Puolitiiviste + vilja & Vehnä & Epäorgaaninen & Munakunta (14 kanaa) \\
\hline
\end{tabular}

Kaikki ruokintakäsittelyt muodostuivat kolmesta rehuvaiheesta. Puolitiiviste-viljaruokinnalla vaiheet toteutettiin lisäämällä puolitiiviste-viljaseoksen viljan ja poikaskalkin osuuksia. Täysrehut suunniteltiin erikseen kutakin vaihetta varten. Täysrehut sisälsivät noin 47-46 \% vehnää, $20 \%$ kauraa ja 18-20 
\% soijarouhetta. Lisäksi rehuihin tehtiin tarvittavat vitamiini- ja kivennäistäydennykset. Puolitiiviste suunniteltiin niin, että sen käyttömäärä olisi noin $50 \%$ dieetistä. Ravintoaineiden suhteet pyrittiin saamaan täysrehuissa ja puolitiiviste-viljaseoksissa mahdollisimman samankaltaisiksi. Ohran suuremman kuitupitoisuuden takia puolitiiviste-ohradieetin energia- ja valkuaispitoisuudet jäivät muita dieettejä alhaisimmiksi.

Rehuseoksista otettiin näyte rehun sekoituksen (täysrehu ja puolitiiviste) tai kanalaan tuonnin yhteydessä (puolitiiviste-viljaseos). Yhdistetyistä rehunäytteistä määritettiin kuiva-aine, raakavalkuainen, raakarasva, raakakuitu ja tuhka sekä kalsium, fosfori, seleeni ja aminohapot. Seleenipitoisuus määritettiin kananmunista kerran jokaisen rehuvaiheen aikana. Seleenipitoisuuden määrittämistä varten kerättiin kaksi näytemunaa kustakin koeyksiköstä (yhteensä 20 munaa ruokintakäsittelyä kohti). Munat yhdistettiin ruokintakäsittelyittäin kuudeksi näytteeksi. Kokeen päätyttyä kerättiin lihanäytteet koipi-reisipalasta kolmelta kanalta kustakin ruokintakäsittelystä lihan seleenipitoisuuden selvittämistä varten. Seleenipitoisuudet määritettiin MIBK-APDC-menetelmällä grafiittiuunitekniikalla.

Tuotantotulosten tilastollinen tarkastelu tehtiin toistettujen mittausten varianssianalyysillä käyttäen seuraavaa mallia: $\mathrm{Y}_{\mathrm{ijk}}=\mu+\mathrm{t}_{\mathrm{i}}+\delta_{\mathrm{i}}+\mathrm{p}_{\mathrm{k}}+(\mathrm{p} \mathrm{x} \mathrm{t})_{\mathrm{ik}}+\varepsilon_{\mathrm{ijk}}$, missä $\mathrm{Y}_{\mathrm{ijk}}=$ havainto, $\mu=$ keskiarvo, $\mathrm{t}_{\mathrm{i}}=$ käsittelyn vaikutus $(i=1, \ldots, 12$ tai $i=1, \ldots, 6), \delta_{i}=$ käsittelyn vaikutuksen virhe, $p_{k}=$ jakson vaikutus $(\mathrm{k}=1, \ldots, 13)$ ja $\varepsilon_{\mathrm{ijk}}=$ koevirhe.

\section{Tulokset ja tulosten tarkastelu}

Keskeisimmät tuotantotulokset koko kokeen ajalta on esitetty taulukossa 2. Häkkimallin päävaikutukset eivät olleet merkitseviä. Havaitut yhdysvaikutukset (taulukko 2) olivat vaikeasti tulkittavia ja kokonaistulosten ja käytännön sovellusten kannalta merkityksettömiä. Täysrehuruokinnalla rehunkulutus oli pienempää kuin puolitiiviste-viljaruokinnalla $(p<0,001)$. Myös rehunmuuntosuhde oli täysrehuruokinnalla parempi kuin puolitiiviste-viljaruokinnalla $(p<0,001)$. Muihin tuotannon tunnuslukuihin ruokintastrategia ei vaikuttanut. Myös aiemmissa tutkimuksissa täysrehuruokitut kanat ovat kuluttaneet vähemmän rehua kuin kokonaista viljaa saaneet kanat (Al-Bustany ja Elwinger 1988, Bennett ja Classen 2003). Tämän kokeen tuloksista poiketen Bennett ja Classen (2003) raportoivat myös munintaprosentin pienenevän kun kanat saivat kokonaista ohraa jauhetun sijasta. Tässä tutkimuksessa kokonaista ohraa puolitiivisteen kanssa saaneissa ryhmissä rehunkulutus oli suurempi kuin ryhmissä, jotka saivat puolitiivisteen kanssa kokonaista vehnää $(\mathrm{p}<0,001)$. Ohran matalampi energiapitoisuus vehnään verrattuna selittänee tämän eron. Muissa tuotantotuloksissa ohra ja vehnä eivät eronneet toisistaan. AlBustanyn ja Elwingerin (1988) tulokset ovat saman suuntaiset tämän kokeen tulosten kanssa myös ohran ja vehnän välisten erojen osalta: vain rehunkulutuksessa ja sen myötä rehunmuuntosuhteessa havaittiin merkitsevä ero.

Seleenilähde ei vaikuttanut kanojen munintaprosenttiin. Ensimmäistä rehuvaihetta lukuun ottamatta orgaanista seleeniä saaneiden kanojen rehunkulutus oli keskimäärin suurempi kuin epäorgaanista seleeniä saaneiden kanojen. Orgaanista seleeniä saaneet kanat munivat ensimmäisen rehuvaiheen aikana suurempia munia kuin epäorgaanista seleeniä saaneet kanat $(\mathrm{p}=0,026)$. Seleeninlähteen vaikutus munan keskipainoon ei kuitenkaan ollut tilastollisesti merkitsevä koko kokeen tuloksia tarkasteltaessa $(\mathrm{p}=0,074)$. Tämän kokeen tulokset ovat samansuuntaiset kuin aiemmassa kokeessa, jossa käytettiin seleenirikastettua hiivaa (Payne ym. 2005).

Rehujen, kananmunien ja lihanäytteiden analysoidut seleenipitoisuudet on esitetty taulukossa 3. Seleenilähde vaikutti selvästi kananmunan seleenipitoisuuteen; orgaanista seleeniä saaneiden kanojen munissa seleeniä oli enemmän kuin epäorgaanista seleeniä saaneiden. Vastaavia tuloksia on saatu myös aiemmin orgaanista ja epäorgaanista seleeniä vertailleissa tutkimuksissa (Payne ym. 2005, Skřivan ym. 2006).

\section{Johtopäätökset}

Orgaanisen seleenilähteen käyttö munivien kanojen rehussa epäorgaanisen sijaan nostaa kananmunien seleenipitoisuutta. Seleenirikastettuja kananmunia voidaan siis tuottaa käyttämällä kanojen rehussa orgaanista seleenilähdettä. 
Taulukko 2. Tuotantotulokset jaksoilla 1-13. Keskiarvot ja $95 \%$ luottamusvälit.

\begin{tabular}{|c|c|c|c|c|c|c|c|c|c|c|c|c|c|c|c|c|c|c|c|c|c|c|c|c|}
\hline Ruokintakäsittely & & 1 & & & & & 2 & & & 3 & 3 & & & 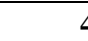 & 4 & & & 5 & ; & & & 6 & & \\
\hline Ruokinta & & Täys & rehu & & & Täys & rehu & & & Puolit & tiiviste & & & Puolit & iiviste & & & Puolit & iiviste & & & Puoliti & iviste & \\
\hline Seleeni & & Orgaa & ninen & & & päorg & aanine & & & Orgaa & aninen & & & Orgaa & aninen & & & päorg: & aaniner & & & päorga & aninen & \\
\hline Vilja & & . & & & & & - & & & OH & hra & & & Vel & hnä & & & Oh & Ira & & & Veh & nä & \\
\hline Häkki & $\mathbf{T}$ & & $\mathbf{M}$ & & $\mathbf{T}$ & & $\mathbf{N}$ & & $\mathbf{T}$ & & $\mathbf{M}$ & & $\mathbf{T}$ & & N & & $\mathbf{T}$ & & $\mathbf{M}$ & & 1 & $\Gamma$ & $\mathbf{M}$ & \\
\hline $\mathbf{N}$ & 7 & & 3 & & 6 & 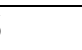 & 4 & . & 7 & & 3 & & 6 & 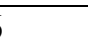 & 4 & & 7 & & 3 & & 7 & 7 & 3 & \\
\hline & $\mathrm{Ka}$ & $+/-$ & $\mathrm{Ka}$ & $+/-$ & $\mathrm{Ka}$ & $+/-$ & $\mathrm{Ka}$ & $+/-$ & $\mathrm{Ka}$ & $+/-$ & $\mathrm{Ka}$ & $+/-$ & $\mathrm{Ka}$ & $+/-$ & $\mathrm{Ka}$ & $+/-$ & $\mathrm{Ka}$ & $+/-$ & $\mathrm{Ka}$ & $+/-$ & $\mathrm{Ka}$ & $+/-$ & $\mathrm{Ka}$ & $+/-$ \\
\hline Munintaprosentti & 92,1 & 1,04 & 89,6 & 2,18 & 91,6 & 1,21 & 93,1 & 1,04 & 90,3 & 1,31 & 93,5 & 1,11 & 90,3 & 1,03 & 92,6 & 1,03 & 91,8 & 0,97 & 92,6 & 0,94 & 90,3 & 1,32 & 90,2 & 1,42 \\
\hline Munan paino & 66,8 & 0,76 & 66,9 & 1,16 & 66,0 & 0,83 & 66,1 & 1,03 & 66,4 & 0,78 & 66,7 & 1,18 & 67,0 & 0,87 & 67,0 & 1,02 & 66,5 & 0,75 & 66,7 & 1,12 & 66,1 & 0,74 & 66,4 & 1,19 \\
\hline $\begin{array}{l}\text { Tuotanto, } \\
\text { g/pv/kana }\end{array}$ & 61,4 & 0,66 & 59,8 & 1,32 & 60,4 & 0,78 & 61,5 & 0,80 & 59,8 & 0,79 & 62,3 & 0,92 & 60,4 & 0,73 & 61,9 & 0,83 & 61,0 & 0,67 & 61,7 & 0,92 & 59,5 & 0,89 & 59,8 & 0,90 \\
\hline $\begin{array}{l}\text { Rehunkulutus, } \\
\text { g/pv/kana } \\
\text { Rehunkulutus, }\end{array}$ & 118,7 & 1,25 & 119,6 & 2,88 & 117,8 & 1,57 & 119,3 & 1,90 & 126,9 & 1,20 & 127,7 & 1,73 & 124,0 & 1,66 & 122,0 & 1,88 & 126,0 & 1,13 & 125,0 & 1,20 & 119,6 & 1,37 & 119,2 & 1,78 \\
\hline $\begin{array}{l}\mathrm{kg} / \mathrm{muna}-\mathrm{kg} \\
\text { Kumulatiivinen }\end{array}$ & 1,94 & 0,03 & 2,01 & 0,07 & 1,96 & 0,03 & 1,94 & 0,04 & 2,13 & 0,03 & 2,05 & 0,03 & 2,06 & 0,03 & 1,97 & 0,03 & 2,07 & 0,03 & 2,03 & 0,03 & 2,02 & 0,03 & 2,00 & 0,04 \\
\hline kuolleisuus & 0 & & 8,9 & 22,2 & 4,2 & 5,36 & 2,2 & 2,72 & 5,4 & 9,10 & 3,0 & 12,8 & 6,3 & 7,19 & 0 & . & 4,5 & 2,82 & 3,0 & 2,56 & 11,6 & 6,180 & 1,8 & 4,44 \\
\hline
\end{tabular}

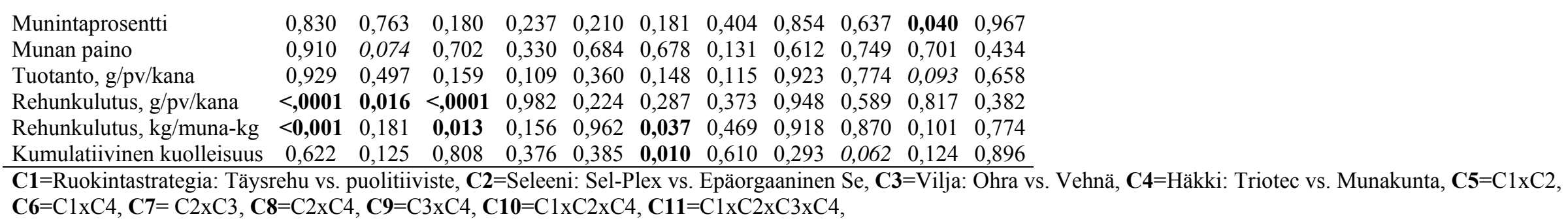


Kokonaisen viljan syöttäminen puolitiivisteen kanssa on tämän kokeen tulosten perusteella käyttökelpoinen ruokintastrategia. Tuotantokustannuksia vertailtaessa on kuitenkin otettava huomioon rehunmuuntosuhde. Hinnaltaan korkeampaa ja ravintoainepitoisuudeltaan tiiviimpää rehua kuluu tuotettua kananmunakiloa kohti yleensä vähemmän kuin hinnaltaan halvempaa rehua. Kokeen tulosten perusteella suurempi rehunmuuntosuhde puolitiiviste-viljaruokinnassa kaventaakin rehukustannusten välistä eroa täysrehu- ja puolitiiviste-viljaruokintojen välillä. Erilaisten ruokintastrategioiden vaikutusta tuotantokustannuksiin on myös tarkasteltava ottaen huomioon käytettävien tehdasvalmisteisten rehujen ja viljojen kulloisetkin hintasuhteet. Koetta suunnitellessa vehnän hinta oli hyvin edullinen. Myöhemmin vehnän hinta on noussut suhteessa enemmän kuin teollisten rehuseosten, joten sen käyttäminen rehuna ei enää alenna rehukustannuksia yhtä paljon kuin aiemmassa hintatilanteessa.

Taulukko 3. Rehujen, kananmunien ja lihanäytteiden analysoidut seleenipitoisuudet.

\begin{tabular}{|c|c|c|c|c|c|c|}
\hline Ruokintakäsittely & 1 & 2 & 3 & 4 & 5 & 6 \\
\hline Ruokinta & Täysrehu & Täysrehu & Puolitiiviste & Puolitiiviste & Puolitiiviste & Puolitiiviste \\
\hline Seleeni ${ }^{1)}$ & $\mathbf{O}$ & EO & $\mathbf{O}$ & $\mathbf{O}$ & EO & EO \\
\hline Vilja & - & - & Ohra & Vehnä & Ohra & Vehnä \\
\hline \multicolumn{7}{|c|}{ Seleenipitoisuus rehussa, $\mu \mathrm{g} / \mathrm{kg}$ ka } \\
\hline I-vaihe & 370 & 390 & 370 & 440 & 390 & 390 \\
\hline II-vaihe & 350 & 410 & 430 & 400 & 430 & 460 \\
\hline III-vaihe & 410 & 350 & 370 & 310 & 310 & 270 \\
\hline \multicolumn{7}{|c|}{ Seleenipitoisuus kananmunassa, $\mu \mathrm{g} / \mathrm{kg}$ ka } \\
\hline I-vaihe & 1310 & 960 & 1450 & 1580 & 980 & 1060 \\
\hline II-vaihe & 1350 & 990 & 1240 & 1290 & 1030 & 1030 \\
\hline III-vaihe & 1460 & 1030 & 1540 & 1550 & 1050 & 1060 \\
\hline \multicolumn{7}{|c|}{ Laskennallinen seleenin saanti, $\mu \mathrm{g} / \mathrm{pv} / \mathrm{kana}$} \\
\hline I-vaihe & 38,1 & 41,0 & 41,2 & 47,2 & 43,6 & 41,1 \\
\hline II-vaihe & 37,0 & 43,2 & 48,4 & 44,3 & 48,1 & 49,0 \\
\hline III-vaihe & 47,0 & 38,8 & 44,4 & 36,3 & 36,2 & 30,7 \\
\hline \multicolumn{7}{|c|}{ Laskennallinen seleenin määrä yhdessä kananmunassa (58 g), $\mu \mathrm{g}$} \\
\hline I-vaihe & 16,1 & 11,7 & 17,6 & 18,9 & 11,7 & 12,7 \\
\hline II-vaihe & 16,6 & 12,1 & 15,1 & 15,5 & 12,3 & 12,3 \\
\hline III-vaihe & 17,9 & 12,6 & 18,7 & 18,6 & 12,6 & 12,7 \\
\hline \multicolumn{7}{|c|}{ Seleenipitoisuus lihassa, $\mu \mathrm{g} / \mathrm{kg}$ ka } \\
\hline & 1333 & 760 & 1267 & 1133 & 793 & 777 \\
\hline
\end{tabular}

\section{Kirjallisuus}

Al-Bustany, Z. \& Elwinger, K. 1988. Whole grains, unprocessed rapeseed and $\beta$-glucanase in diets for laying hens. Swedish J. Agric. Res. 18: 31-40.

Bennett, C.D. \& Classen, H.L. 2003. Performance of two strains of laying hens fed ground and whole barley with and without access to insoluble grit. Poult. Sci. 82:147-149.

Buckley, W.T. 2000. Trace element dynamics. In: D’Mello, J.P.F.(ed.). Farm Animal Metabolism and Nutrition, Oxon, CABI Publishing. p. 161-182.

Hetland, H., Svihus, B. \& Olaisen, V. 2002. Effect of feeding whole cereals on performance, starch digestibility and duodenal particle size distribution in broiler chickens. Br. Poult. Sci. 43:416-423.

Hetland, H., Svihus, B. \& Krogdahl, Å. 2003. Effects of oat hulls and wood shavings on digestion in broilers and layers fed diets based on whole and ground wheat. Br. Poult. Sci. 44:275-282.

Jacques, K.A. 2002. Selenium metabolism in animals The relationship between dietary selenium form and physiological response. Feed Compounder 22:14-21.

Payne, R.L., Lavergne, T.K. \& Southern, L.L. 2005. Effect of inorganic versus organic selenium on hen production and egg selenium concentration. Poult. Sci. 84:232-237.

Schrauzer, G.N. 2000. Selenomethionine: A review of its nutritional significance, metabolism and toxicity. J. Nutr. 130:1653-1656.

Skřivan, M., Šimáně, J., Dlouhá, G. \& Doucha, J. 2006. Effect of dietary sodium selenite, Se-enriched yeast and Se-enriched Chlorella on egg Se concentration, physical parameters of eggs and laying hen production. Czech J. Anim. Sci 51:163-167.

Surai, P.F. 2002. Selenium in poultry nutrition 1. Antioxidant properties, deficiency and toxicity. World's Poult. Sci. J. 58:333-347. 